\title{
A racionalização da burocracia por meio de uma tecnologia inovadora: Blockchain
}

\section{Rationalizating bureaucracy through innovative technology: Blockchain}

\author{
Marcos Antonio Franklin \\ https://orcid.org/0000-0003-1102-3315 \\ Alexandre Nabil Ghobril \\ https://orcid.org/0000-0001-9866-0290 \\ Bruno Nunes Trevelin \\ https://orcid.org/0000-0001-8852-1940 \\ Cesar Nessim Azar \\ https://orcid.org/0000-0002-8421-0819 \\ Guilherme Brandão Costa e Silva \\ https://orcid.org/0000-0002-5868-1377 \\ Guilherme Oliveira de Paulo \\ https://orcid.org/0000-0001-8772-6207 \\ Luiz Cláudio Brandão Farjalla \\ https://orcid.org/0000-0003-2888-6977
}

Doutor em Administração. Universidade Presbiteriana Mackenzie (UPM) - Brasil.

franklin.marcos@gmail.com

Doutor em Administração. Universidade Presbiteriana Mackenzie (UPM) - Brasil.

alexandre.ghobril@mackenzie.br

Bacharel em Administração de empresas pela Universidade Presbiteriana Mackenzie (UPM) -

Brasil. brunonunest@gmail.com

Bacharel em Administração de empresas pela Universidade Presbiteriana Mackenzie (UPM) Brasil. cesar.azar@outlook.com

Bacharel em Administração de empresas pela Universidade Presbiteriana Mackenzie (UPM) Brasil. guilher1237@gmail.com

Bacharel em Administração de empresas pela Universidade Presbiteriana Mackenzie (UPM) Brasil. guilhermeoliveiradepaulo@hotmail.com

Bacharel em Administração de empresas pela Universidade Presbiteriana Mackenzie (UPM) -

Brasil. Ifarjalla@yahoo.com.br

\section{RESUMO}

Este artigo buscou abordar como o uso do blockchain pode racionalizar a burocracia dentro de empresas que buscam eficiência e confiabilidade em seus processos. O estudo foi realizado em duas empresas de diferentes segmentos, sendo, a primeira, uma fábrica de produtos cosméticos que utiliza a ferramenta em seu processo logístico da entrega de seu produto a distribuidores e, a segunda, uma multinacional de consultoria gerencial e auditoria na área da saúde. A pesquisa, de caráter exploratório, utilizou entrevistas em profundidade com dirigentes das empresas alvo. As entrevistas foram transcritas e analisadas utilizando a proposta metodológica de Flores (1994) que, a partir dos dados obtidos estabeleceu as categorias e, posteriormente, as metacategorias. Os resultados mostraram como o blockchain pode simplificar e remodelar processos e transações entre as empresas, reduzindo erros e retrabalho, tornando processos burocráticos mais racionais e dessa forma, mais eficientes.

Palavras-chave: inovação; blockchain; burocracia; tecnologia; racionalização.

\section{ABSTRACT}

This article sought to analyze how the use of blockchain can rationalize bureaucracy within companies that seek efficiency and reliability in their processes. The study was carried out in two companies of two different segments: one is a cosmetics factory that uses the tool in its logistical process of delivering its products to distributors; the second is a multinational management consulting and auditing firm in the health area. The research, of an exploratory nature, used in-depth interviews with directors of the target companies. The interviews were transcribed and analyzed using the methodological proposal of Flores (1994) which, based on the data obtained, established the categories and, subsequently, the meta-categories. The results showed how blockchain can simplify and reshape processes and transactions between companies, reducing errors and rework, making bureaucratic processes more rational and thus more efficient.

Keywords: innovation; blockchain; bureaucracy; technology; rationalization.

Recebido em 14/05/2021. Aprovado em 27/06/2021. Avaliado pelo sistema double blind peer review. Publicado conforme normas da ABNT. https://doi.org/10.22279/navus.2022.v12.p01-17.1612 


\section{INTRODUÇÃO}

Assumindo que o cerne da inovação é a incorporação de novos processos e ferramentas que melhoram a eficiência ou efetividade de processos antigos, esse projeto buscou explorar o potencial da tecnologia blockchain e suas propriedade, além de proporcionarem confiança nas relações entre entidades mediante a evidenciação do conceito e a modelagem dessa tecnologia revolucionam o meio em que os negócios são feitos ou as informações são trocadas, possibilitando assim, o uso dessa nova ferramenta a fim de otimizar a burocracia nessas relações e nos processos.

Dessa forma, foi possível apresentar às empresas e instituições, o que deve ser considerado antes e depois de implementar blockchain em algum de seus processos, quais os desafios de implementação que podem vir a ocorrer e quais são os benefícios que essa tecnologia pode trazer no quesito de diminuição de peso burocrático. Este artigo buscou abordar como o uso da ferramenta inovadora blockchain pode racionalizar a burocratização dentro de empresas que buscam eficiência e confiabilidade em seus processos, e para isso, foi elaborado o seguinte problema de pesquisa: como o uso do blockchain pode racionalizar os processos burocráticos? O objetivo, geral foi investigar como o uso do blockchain pode racionalizar os processos burocráticos. Assim, definiram-se os seguintes objetivos específicos: i) conhecer os processos burocráticos dentro da organização que utilizam a tecnologia blockchain; ii) identificar quais os benefícios do blockchain em processos burocráticos; iii) identificar quais as barreiras para a utilização da tecnologia blockchain no processo burocrático.

O estudo foi realizado em duas empresas de diferentes segmentos, a primeira delas uma fábrica de produtos cosméticos situada no interior de São Paulo que utiliza a ferramenta em seu processo logístico da entrega de seu produto a distribuidores e a segunda, uma empresa multinacional de consultoria gerencial e auditoria na área da saúde. Optou-se pelo tipo de pesquisa exploratória segundo Piovesan e Temporini (1995), e pelo método qualitativo, conforme Richardson (2007).

Para a coleta de dados foram realizadas entrevistas, com roteiros semiestruturados, de acordo com Flick (2009). As entrevistas foram escritas e analisadas por meio da análise de dados de acordo com a proposta de Flores (1994). Os resultados mostraram como o blockchain está revolucionando o processo logístico dentro de empresas que utilizam a ferramenta para tal fim, deixando processos burocráticos mais racionais e dessa forma, mais eficientes. Este artigo está estruturado, por esta introdução, pelo referencial teórico, pelos procedimentos metodológicos e considerações finais.

\section{REFERENCIAL TEÓRICO}

Nesta seção serão apresentadas as teorias utilizadas no desenvolvimento deste estudo são elas: burocracia; inovação; tecnologia e blockchain.

\subsection{Burocracia}

A burocracia começou a ser praticada há muito tempo, podendo ser observada a partir das civilizações antigas, pois era uma classe de funcionários, podendo ser chamados de burocratas, que possuíam o Estado como propriedade, como se pode observar até os dias de hoje, na sociedade. Porém o capitalismo tornou a burocracia em um termo voltado mais para o capital. Isso porque ela prende o pensamento do homem a pensar somente em prestígios e cargos hierárquicos mais altos e, com o capitalismo, significa mais capital, que é o objetivo da maioria das pessoas (MOTTA, 1988).

A burocracia tem um lado positivo enegativo. O lado positivo guia e deixa claras as responsabilidades de um funcionário, fazendo com que ele se sinta mais eficiente e não tenha um estresse de cargo. Já o negativo reprime a criatividade, desmotiva os funcionários e, consequentemente, promove o descontentamento perante a organização (ADLER; BORYS, 1996). Segundo o sociólogo Weber (1963), a burocracia tem o objetivo de deixar processos mais eficientes, buscando uma estrutura hierárquica para uma maior eficiência, que 
continha divisão de trabalho, hierarquia de autoridade, racionalidade, regras e padrões, compromisso profissional, registro escrito e impessoalidade.

Segundo Bourns (1994), as características da teoria de Weber foram as responsáveis por criar a imagem de burocracia sendo algo negativo, isso porque ele via como forças características como criar regras, rotinas e criação de arquivos e formulários, acreditando que geraria precisão, velocidade e redução em materiais e funcionários, criando um nível esperado com a burocracia. Diferentes autores se referem à burocracia sendo um sinônimo para ineficiência, preferindo um método de gestão puxado para o Taylorismo. Para eles, as burocracias são grandes gastos e fazem isso de forma ineficiente (BOURNS, 1994). Outros autores como Bresser Pereira e Prestes Motta que caracterizam a burocracia como um sistema altamente organizado, ou seja, quanto mais organizada a empresa, mais poderá ser considerada burocratizada, onde a divisão de trabalho e o poder têm que ser seguidos exatamente conforme as regras (PERSSON; CHAGAS; DASBRINGHENTI, 2015).

Muitos acreditavam que o conceito tradicional de burocracia iria se romper durante o tempo, e essa ideia se fortificou com a chegada das organizações mais modernas, que estão dispensando o modelo tradicional de controle, optando por outras maneiras que empoderam seus funcionários para que tenham mais poder de decisão. Essa é uma medida que gera um grande impacto tanto na sociedade como nas organizações, pois as pessoas precisam se adaptar ao novo modelo (VASCONCELOS, 2004). Uma das críticas que se faz ao Modelo Burocrático é o enfoque baseado na previsibilidade e estabilidade, sem levar em consideração as alterações no cenário externo, a qualificação dos membros da organização e a tecnologia e seus avanços. A teoria burocrática possui uma postura técnica e mecanicista. Sendo assim, pode-se citar como vantagens do modelo, a consistência e a eficiência. Já como desvantagens estão os excessos de rigidez e a lentidão na execução dos processos (ANDRADE; AMBONI, 2007).

Porém ao longo do tempo as fábricas se modernizaram e com o aumento tecnológico ocorreram grandes avanços nos seus modelos de produção e operação. Com isso a relação de trabalho foi alterada e isso trouxe mudanças no modo como as pessoas se relacionam nas organizações caracterizando uma diferença entre a fábrica e a organização (MATOS; LIMA, 2007). O avanço da tecnologia nos trouxe uma nova ferramenta, o blockchain, que tem muito em comum com a burocracia. Para começar, pode-se entender que o blockchain é uma forma mais eficiente da burocracia, pois segue regras pré-definidas do mesmo modo que a burocracia, uma vez que ele também traz funções como o processamento de informações da sociedade (JUN, 2018).

Como o blockchain é uma nova tecnologia, ele traz mais eficiência e confiança do que a burocracia tradicional, agregando outras funções importantes como uma maior eficiência, por ser um sistema computadorizado que automatiza processos. E isso em um tempo menor do que a burocracia já que não é totalmente concentrado em atividades humanas. Por isso, o blockchain pode ser considerado uma nova forma de burocracia (JUN, 2018).

\subsection{Inovação}

Drucker (2004), define a inovação como uma função do empreendedorismo, um meio pelo qual o empreendedor cria recursos geradores de riqueza ou potencializa sua geração de riqueza. Existem inovações que provêm de rasgos de genialidade, no entanto, a maioria das inovações e, especialmente, as de maior sucesso, resultam de uma procura consciente e intencional de oportunidades de inovação que se resumem a apenas algumas situações.

A inovação pode ocorrer em produtos, processos, mercados e em novos modelos de negócio. 0 termo inovação em produto abrange tanto bens como serviços. Na maioria das economias, o setor de serviços representa uma grande maioria das atividades, então é provável que exista bastante espaço para investimentos e inovações. A onda da internet mostrou que grandes empresas como Google, Amazon e Skype encontraram maneiras de inovar em seus serviços, trazendo um grande avanço para os mesmos (TIDD; BESSANT, 2015).

O questionamento sobre inovação em serviços é bastante novo e controverso. Concentra-se, na maior parte das vezes, em inovação de processos, que embutem melhorias e novas tecnologias no ciclo operacional. 
Os processos empresariais são fluxos de valor que devem ser identificados, analisados e melhorados continuamente para satisfazer as necessidades do cliente, a existência de um bem ou serviço é sempre acompanhada de um conjunto de processos. Portanto, um adequado gerenciamento dos processos empresariais vai ter impacto direto na qualidade dos bens e serviços fornecidos pela empresa, gerando uma vantagem competitiva (DÁVILA; VARVAKIS; LEOCÁDIO, 2008).A maior parte das inovações é de caráter incremental, muitas delas imperceptíveis para o consumidor, podendo gerar crescimento da eficiência técnica, aumento da produtividade, redução de custos, aumento de qualidade e mudanças que possibilitem a ampliação das aplicações de um produto ou processo. A otimização de processos de produção, o design de produtos ou a diminuição na utilização de materiais e componentes na produção de um bem podem ser consideradas inovações incrementais (LEMOS, 2009).

De outro lado, novas tecnologias introduzidas em produtos ou processos e combinadas em novos modelos de negócio são capazes de gerar inovações que transformam a dinâmica de um determinado mercado. Esse tipo de inovação, que Christensen (2006) denomina de inovação disruptiva, descreve um processo pelo qual um produto ou serviço inicia por aplicações simples, na "parte inferior" de um mercado e, progressivamente, se move para "acima do mercado", deslocando ou eliminando concorrentes estabelecidos. Este modelo de inovação permite acesso a produtos ou serviços até então inacessíveis para parte da população.

\subsection{Tecnologia}

Sendo componente fundamental nas organizações, a tecnologia contribui para um melhor fluxo de informações entre os departamentos e entre diferentes empresas, por meio de dispositivos de hardware e software que geram tratamento e armazenamento da informação. Além da conectividade, a tecnologia proporciona eficiência nos produtos e serviços, trazendo melhorias que agregam valor para o cliente, em seus processos e operações, coordenando e integrando as atividades que os compõem, com vistas à redução de custos e o lucro; assim como também na tomada de decisão, proporciona maior visão e entendimento da situação para que a mesma seja a mais assertiva possível (SANTOS, 2019).

Santos (2019) entende que as tecnologias ocupam um papel relevante, desde que associadas a gestão dos setores empresariais, independentemente de seu ramo de atividade, podendo com isso, obter vantagem competitiva fazendo uso dos aparatos tecnológicos.

No campo da inovação, vê-se a forte correlação da mesma com a tecnologia, que se reinventa pela inovação de suas composições e de utilidade, remodelagem utilizada como estratégia para obter diferenciais competitivos, melhorias internas e preservação do meio ambiente, pode manter assim a organização atualizada e preparada perante suas rivais (BAPTISTA, 2019).

Andriotti et al. (2018) apontam que em relação à estrutura e organização de TI, normalmente a divisão ocorre em duas áreas operacionais, desenvolvimento e produção, sendo a segunda subdividida em suporte e central de dados e, a primeira, aplicações específicas são designadas em cada negócio da empresa. A central de dados consiste em uma estrutura de recursos na rede segura, que usa sua infraestrutura para armazenamento e compartilhamento de dados, como informações do cliente, dados financeiros, documentos, entre outros, sendo o suporte responsável por performar o controle de sua disponibilidade. Consolidada a TI nas empresas e o foco da tecnologia em inovação contínua, a fim de se manterem competitivas no mercado, novas tecnologias vêm sendo criadas e tem se destacando entre elas: o cloud computing, internet das coisas, $5 G$, inteligência artificial, big data e o blockchain, que já são utilizadas e trazem diversos benefícios, em grandes e até em pequenas empresas.

Marchisotti, Joia e Carvalho (2018) definem o cloud computing como um modelo de serviço de TI, onde os serviços de computação - hardware e software - são entregues sob demanda para os clientes, por meio de uma rede de dados, em forma de autoatendimento, independente do dispositivo e da localização. Assim, o cloud computing faz parte do conceito de computação utilitária, provisionando seus recursos na rede para armazenamento e tratamentos de dados em bytes, centralizado em um servidor físico. Dessa forma a TI consegue padronizar seus serviços no cloud, facilitar e aperfeiçoar sua mensuração e respectivas alocações de 
custos, levando em consideração o que foi de fato utilizado, dispor os dados de forma imediata, confiável e segura, dando a empresa maior acesso a inovação e tecnologias (MENDONÇA; ANDRADE; SOUSA NETO, 2018).

Outra tecnologia que se apresenta de forma real é a Inteligência Artificial (IA) que é o estudo da relação das partes cognitiva e computacional, ciência que envolve o computador com comportamentos inteligentes, de maneira que aprendam por si próprios por meio de códigos de programação, os fatores mais essenciais e complexos na prática da IA (BARR; FEIGENBAUM, 1982). Após a revolução industrial, digital e da informação, a sociedade teve mudanças em sua essência e comportamentos, principalmente no de consumo e, agora uma nova revolução vem sendo formada, a da IA.

O conceito Big Data pode ser definido como uma técnica, que utiliza o escopo de uma base de dados de alta escala, e suas respectivas ferramentas da análise, extraindo todo potencial da informação e traduzindo em forma de vantagem competitiva. Considerado multidimensional, cada abordagem de observação e análise pode considerar variáveis distintas e, logo, gerar resultados também distintos. $O$ termo é visto como uma descrição mais detalhada e precisa em relação ao comportamento do consumidor, também como conceito mais amplo das tendências tecnológicas que possibilitam novas formas de abordagem, para que melhor compreensão do mundo e da sociedade, tomando decisões corretas (NETTO; SLONGO, 2019).

\subsection{Blockchain}

Segundo Gaur, Cuomo e Arun (2019), o blockchain é uma tecnologia que está pronta para inaugurar uma nova maneira de conduzir negócios e que mudará a vida cotidiana para melhor. Ele cria uma estrutura de incentivos e capacita grupos de instituições a alcançarem melhores resultados, criando oportunidades de crescimento que, juntos, são maiores do que as façanhas que um único membro poderia alcançar sozinho. Além de impacto nos negócios e no setor privado, o blockchain pode trazer disrupção para toda economia global, trazendo soluções para problemas políticos e socioeconômicos que vários países sofrem atualmente. Assim, a tecnologia está atraindo a atenção de diversos players e áreas, que vão de governos até investidores de risco (GAUR; CUOMO; ARUN, 2019).

O blockchain é uma das principais tecnologias por trás do bitcoin, a primeira criptomoeda descentralizada e bem-sucedida da história. Como plataforma financeira, o bitcoin exige um ledger (livrorazão) digital para registrar todas as transações que ocorrem entre usuários da criptomoeda. A maneira como esse ledger foi projetada é o que levou ao surgimento de tecnologias blockchain (ZAMBRANO, 2017). Blockchain é caracterizado por uma lista ordenada de blocos, em que cada bloco é identificado por seu hash criptográfico. Cada bloco faz referência ao bloco que veio antes dele, resultando em uma cadeia de blocos. Cada bloco consiste em um conjunto de transações. Depois que um bloco é criado e anexado à blockchain, as transações nesse bloco não podem ser alteradas ou revertidas. Isso é para garantir a integridade das transações e evitar problemas de gastos duplos (ALHARBY; VAN MOORSEL, 2017).

Além da lista ordenada de blocos, o blockchain tem como uma das propriedades principais proporcionar uma rede composta por "nós completos" ou full nodes, eles são como um computador executando um algoritmo que está protegendo a rede. Cada nó contém um registro completo de todas as transações que já foram registradas nessa blockchain (LAURENCE, 2019). Ao contrário de outros ledgers e plataformas transacionais tradicionais, novos blocos só podem ser adicionados quando os nós da rede chegarem a um consenso. Ocorre um consenso descentralizado, substituindo a necessidade de uma autoridade central de confiança. Por isso que blockchain é caracterizado como uma tecnologia em que a confiança é descentralizada: a própria rede fornece confiança entre todos os pares (ZAMBRANO, 2017).

Quando se entra nos tipos de blockchain, pode-se considerar os públicos, como o bitcoin, que são grandes redes distribuídas executadas por uma criptomoeda nativa. Uma criptomoeda é um bit único de dados que pode ser negociado entre duas partes. As blockchains públicas estão abertas para qualquer pessoa participar em qualquer nível e possuem código-fonte aberto que a sua comunidade mantém (LAURENCE, 2019). Também tem os blockchains privados, conhecidos como DLT (Distributed Ledger Technology), porém tendem a ser menores e não utilizam token ou criptomoeda. Os membros são controlados de perto. Esses tipos de blockchains são favorecidos por consórcios que possuem membros confiáveis e trocam informações 
confidenciais (LAURENCE, 2019). Nos blockchains privados, existem diferentes níveis de permissão, como por exemplo, o direito de participar do "consenso de rede" em transações, com permissões atribuídas aos participantes dessa rede. Esses sistemas têm associação fixa, ou seja, o número de parceiros na rede é conhecido. Como todos os participantes são identificados, acordos contratuais podem ser estabelecidos entre eles para penalizar alguma má conduta (RAUCHS et al., 2019). As blockchains privadas criam confiança, distribuindo dados por meio de uma rede de participantes conectados, mas independentes, conhecidos um pelo outro e que podem ser responsabilizados por algum ato fraudulento (LAURENCE, 2019).

\subsubsection{Contratos inteligentes}

Um contrato inteligente é um código executável que roda na blockchain para facilitar, executar e aplicar os termos de um acordo. Seu principal objetivo é executar automaticamente os termos de um acordo uma vez que as condições especificadas sejam atendidas. Assim, esses contratos prometem baixas taxas de transação comparadas aos sistemas tradicionais que exigem que um terceiro confiável imponha e execute os termos de um contrato. A ideia de contratos inteligentes veio de Szabo em 1994. No entanto, a ideia não viu a luz até o surgimento da tecnologia blockchain. Um contrato inteligente pode ser pensado como um sistema que libera ativos digitais para todos ou algumas das partes envolvidas uma vez que regras pré-definidas arbitrárias sejam cumpridas (ALHARBY; VAN MOORSEL, 2017).

Gaur, Cuomo e Arun (2019) entendem que se o Blockchain 1.0 (representado pelas criptomoedas) trouxe a descentralização do dinheiro e pagamentos, o Blockchain 2.0 (representado pelos contratos inteligentes) traz a descentralização dos mercados em geral, contemplando a funcionalidade de transferência de qualquer tipo de ativo. Ou seja, pode-se inserir qualquer tipo de documento na rede blockchain e garantir sua autenticidade, tendo uma visão de todo o seu histórico, e a alteração do mesmo só pode ser realizada por meio de um consenso.

Dessa forma, contratos inteligentes são uma nova maneira de construir confiança na transação de ativos e estruturar acordos entre indivíduos, onde a tecnologia do blockchain supre de maneira eficiente a necessidade de um intermediário em determinadas relações onde há problemas de conflitos de informações. Mediante funções programadas no contrato, pode-se aplicar termos de determinado acordo e automatizar alguns processos. Os contratos inteligentes foram introduzidos para mundo por meio da criação do Ethereum pelo Buterin (2015). O Ethereum é uma infraestrutura de computação de código aberto e descentralizada que executa os contratos inteligentes. Ele usa uma blockchain para sincronizar e armazenar as alterações de estado do sistema, juntamente com uma criptomoeda chamada ether para medir e restringir os custos de recursos de execução (ANTONOPOULOS; WOOD, 2019).

\subsubsection{Aplicações}

Os negócios e o comércio, nas últimas décadas, se espalharam globalmente ultrapassando barreiras geográficas e se tornaram abertos de várias maneiras. Em meio a esse cenário, o maior desafio continua sendo a confiança. Em muitos casos, os parceiros de negócio possuem uma confiança limitada ou nenhuma. Por isso, a inclusão de um intermediário geralmente é necessária para garantir suas transações comerciais (GAUR; CUOMO; ARUN, 2019). Nessa estrutura centralizada, onde as organizações têm uma visão muito limitada ou até nenhuma visão, confiança e transparência entre seus parceiros de negócio, acaba resultando em custos elevados, redução na agilidade transações, ineficiência nas operações e cria uma cultura insustentável na economia (GAUR; CUOMO; ARUN, 2019).

Confiar em uma instituição requer muita pesquisa e conhecimento. $O$ blockchain pode superar esses problemas implementando aplicativos de forma descentralizada e segura, garantindo algum nível de certeza. Essa foi uma das principais razões por trás da ampla adoção da blockchain em uma sociedade sem confiança (RAJ, 2019). A natureza distribuída da tecnologia blockchain, juntamente com a ênfase no consenso e nos contratos inteligentes, oferece uma rede de negócios autônoma que simplifica as estruturas corporativas tradicionais em uma estrutura distribuída e compartilhada. As transações comerciais são gerenciadas em um 
ledger distribuído e compartilhado, que oferece transparência e visibilidade na rede sem uma natureza hierárquica e complexa (GAUR; CUOMO; ARUN, 2019).

Os computadores pessoais e a Internet foram duas tecnologias revolucionárias testemunhadas no século 20. A próxima tecnologia significativamente transformadora no século 21 é o blockchain. Segundo Gaur, Cuomo e Arun, (2019, p. 51) a "Gartner prevê que o valor comercial impulsionado pelo blockchain chegaram a US\$3,1 trilhões até 2030". Esse valor comercial será oriundo das diversas oportunidades de transformação de negócios, com vários casos de uso numa ampla gama de indústrias (GAUR; CUOMO; ARUN, 2019). Empresas e instituições de quase todos os setores e indústrias da economia global têm explorado o potencial da tecnologia blockchain nos últimos anos. No entanto, nenhum outro setor chegou perto do setor de Finanças e Seguros no que diz respeito à implantação de redes blockchain corporativas ativas: quase metade de todas as redes cobertas foram lançadas por instituições financeiras (RAUCHS et al., 2019), conforme Figura 1.

Figura 1 - Blockchain network

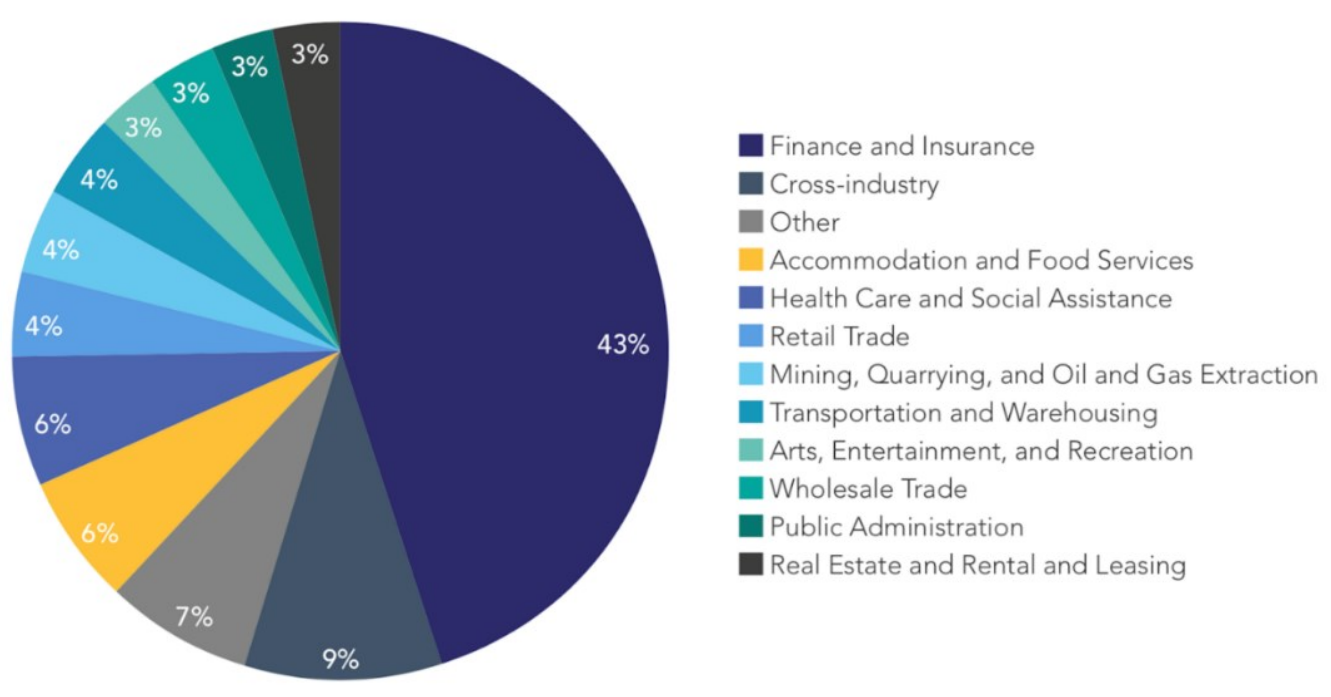

Fonte: Rauchs et al. (2019).

Para exemplificar como o blockchain está ajudando e/ou pode ajudar o sistema financeiro atual, com os recursos oriundos da tecnologia, os bancos podem melhorar a experiência dos clientes, reduzindo o tempo de transação de horas para segundos, além de eliminar processos manuais e eliminar intermediários desnecessários em finanças comerciais, identidades digitais e pagamentos internacionais (GAUR; CUOMO; ARUN, 2019).

Os contratos inteligentes baseados em blockchain podem armazenar, proteger e trocar automaticamente detalhes do contrato e termos financeiros; coordenar logística e pagamentos comerciais por meio de uma rede integrada em tempo real e agilizar os processos de comércio digital. Com o blockchain, as transações contábeis podem fluir de uma pequena empresa para outra por meio de um banco confiável. As empresas maiores também podem se beneficiar com um melhor rastreamento das transações de financiamento comercial (GAUR; CUOMO; ARUN, 2019). No mercado imobiliário, o blockchain pode trazer grandes benefícios em diversas áreas, como gerenciamento de títulos, melhorando a rastreabilidade pela transparência e imutabilidade de dados. Na área de investimentos, a tokenização de ativos possibiliza o investimento em propriedades por meio da compra de uma moeda digital (RAUCHS et al., 2019).

Isso trará muito mais liquidez para investimentos, pois existirá a possibilidade de comprar e vender propriedades em pedaços cada vez menores, mais disponibilidade e uma documentação mais fácil. Todos os acordos podem ser automatizados, pagamentos podem ser enviados e recebidos de maneira instantânea $E$ 
isso pode ser realizado numa escala global, sem a necessidade de intermediários, assim gerando ainda mais valor para as partes envolvidas. Esses benefícios abrirão mercados para novos investidores e permitirão que um número maior de partes gerencie a propriedade, a liquidez e os riscos (DON; RAJAH; OTT, 2019), de acordo com a Figura 2.

Figura 2 - Tokenization

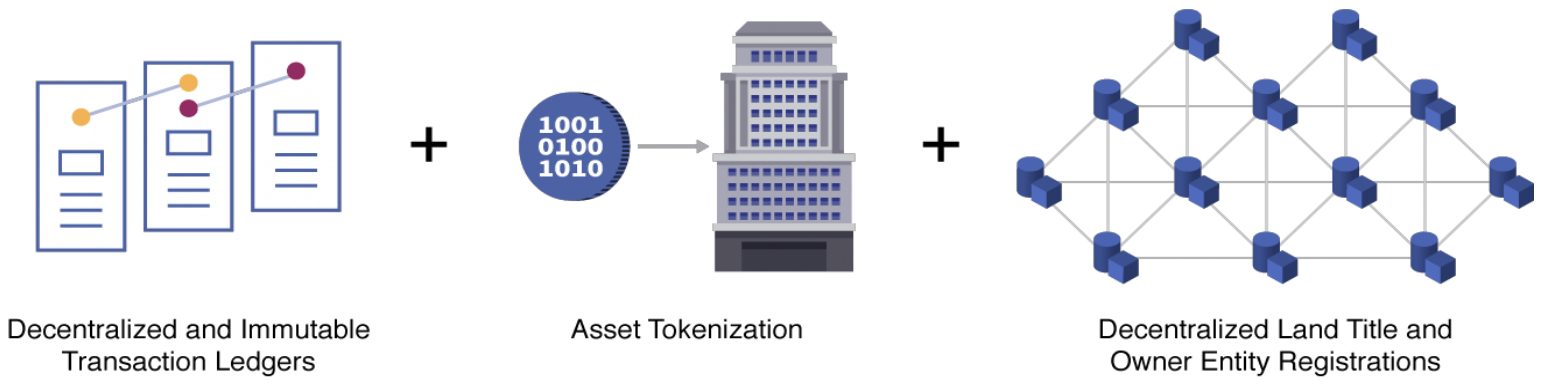

Fonte: Don, Rajah e Ott (2019).

\subsubsection{Vantagens e desafios}

Os blockchains públicos, como o utilizado no bitcoin, sendo uma tecnologia emergente, atualmente enfrenta desafios em sua implementação e processos. Pela sua estrutura recente, só é possível adicionar um novo bloco de transações a cada dez minutos; tamanho dos blocos tem capacidade de 1 megabyte, que equivale a 2.200 transações; altos custos em hardware para rodar as evidências de funcionalidade dos algoritmos; consumo de energia elevado, estima se que o bitcoin consuma o mesmo que 280.000 casas norteamericanas por ano (ZAMBRANO, 2017). Quanto maior os "blocos", maior a quantidade de dados armazenados e menor a velocidade de processamento do sistema, logo uma tendência de centralização do blockchain vem surgindo gradualmente, pelos usuários normalmente optarem em manter seus "blocos" maiores e entre usuários selecionados, a fim de se processar os dados com eficiência de tempo. Entretanto, quando se altera o tamanho dos "blocos" da cadeia, a segurança da criptografia passa a ser outro desafio, devido à complexidade dos algoritmos (ZHENG et al., 2018).

Outro desafio que deve ser considerado é a complexidade da tecnologia, para pessoas comuns é basicamente incompreensível o entendimento técnico do blockchain, sua criptografia possui mecanismos que estão além da capacidade da maioria dos usuários (ZAMBRANO, 2017). O Ecossistema público do blockchain tem características proativas e já trabalha para driblar algumas dessas limitações, como a criação de interfaces mais intuitivas, documentações e melhorias de desempenho. Pelo código ser de caráter aberto "open source", algumas vezes a sua essência pode ser questionada, contudo as mudanças feitas nos códigos só podem ser realizadas de fato quando há um consenso entre os nodes, ou uma decisão da maioria (ZAMBRANO, 2017).

A regulamentação também é um grande desafio para o blockchain, os contratos inteligentes, de execução automática, contêm um conjunto de condições sob as quais um comprador e um vendedor está de acordo. Quando essas condições são cumpridas, o contrato é automaticamente aplicado, algo que os proponentes dizem ser mais eficiente do que contratos em papel. Mas a Deloitte destaca que as regulamentações existentes não cobrem contratos inteligentes, o que podem inibir o investimento em blockchain. No entanto, a Deloitte aponta que algum progresso está sendo feito na frente regulatória, com 17 legislaturas estaduais dos EUA ponderando ou aprovando projetos de lei relacionados à adoção da blockchain (BROWNE, 2018). Segundo Gaur, Cuomo e Arun (2019), quando se fala especificamente de blockchains privados, os mais comumente utilizados no meio empresarial, os desafios não giram em torno de ter uma tecnologia perfeita e amadurecida, pois a tecnologia se encontra em constante avanço desde o surgimento do bitcoin e outras criptomoedas subsequentes, e ultimamente muitas organizações investiram para garantir que a tecnologia tenha adaptabilidade a cada vez mais indústrias. 
Os principais desafios do blockchain são escolher o escopo correto de projeto, garantir que a solução gere valor para todos os participantes da rede, ter uma estrutura de governança bem modelada e ter uma equipe e tecnologias corretas (FERREIRA; PINTO; SANTOS, 2017). É importante desenvolver uma estrutura de incentivos apropriada para que todos se motivem e atuem como parceiros confiáveis na rede. Os maus atores de uma rede podem comprometer a capacidade de atingirem objetivos dentro das condições planejadas de tempo, custos e recursos (GAUR; CUOMO; ARUN, 2019). A governança é o requisito mais crítico e obrigatório para o sucesso de um projeto de implementação de blockchain, porque mantém uma propriedade descentralizada com negócios auto executáveis e contratos legais que são incorporados nas transações como contratos inteligentes. Embora essa abordagem gere automação, velocidade e eficiência em uma rede comercial, é fundamental entender como os contratos inteligentes são desenvolvidos e gerenciados como parte da estrutura de governança. Em situações imprevisíveis, quando você tem parceiros confiáveis e motivados em uma rede, a construção de consenso se torna muito mais fácil e ocorre muito mais rapidamente (GAUR; CUOMO; ARUN, 2019).

\section{LOCUS DA PESQUISA}

O Quadro 1 apresenta as empresas onde foi realizado o estudo. A fim de preservar o anonimato das empresas, foram utilizados nomes fictícios.

Quadro 1 - Caracterização das empresas estudadas

\begin{tabular}{|c|l|}
\hline $\begin{array}{c}\text { Empresa } \\
\text { Alfa }\end{array}$ & $\begin{array}{l}\text { A empresa Alfa é uma fábrica de produtos cosméticos que direciona suas vendas para } \\
\text { distribuidoras e clientes finais por meio de revendedores. Fundada em 2016, em São } \\
\text { José do Rio Preto, sempre buscou serviços inovadores para melhor satisfação de seus } \\
\text { stakeholders. }\end{array}$ \\
\hline $\begin{array}{c}\text { Empresa } \\
\text { Beta }\end{array}$ & $\begin{array}{l}\text { A empresa Beta é uma multinacional de consultoria gerencial e auditoria que atua em } \\
\text { diferentes setores, como o de saúde. A empresa conta com mais de } 312.000 \\
\text { funcionários em 150 localidades. }\end{array}$ \\
\hline
\end{tabular}

Fonte: Elaborado pelos autores (2020).

\section{PROCEDIMENTOS METODOLÓGICOS}

Neste estudo foi realizada uma pesquisa exploratória, que segundo Piovesan e Temporini (1995), é um estudo preliminar que tem como propósito tornar familiar o objeto de estudo investigado, de forma precisa e de fácil compreensão. O método utilizado foi o qualitativo segundo Richardson (2007), os estudos que empregam uma metodologia qualitativa podem descrever a complexidade de determinado problema, analisar a interação de certas variáveis, assim como compreender e classificar processos dinâmicos vivenciados por grupos sociais. Com o planejamento concluído, iniciou-se um processo de síntese e consolidação da teoria e tentativa de formulação de hipóteses. Como instrumento de coleta de dados foi utilizado um roteiro de perguntas semiestruturado. As perguntas foram elaboradas com base em uma matriz de amarração e conectadas aos objetivos específicos e à literatura científica. O guia de entrevista prepara o pesquisador e garante a manutenção do foco da conversa, permite ainda algum improviso sobre as questões (FLICK, 2009).

A coleta de dados foi feita por meio de entrevistas em profundidade. Na escolha dos sujeitos, foram escolhidos e selecionados de forma intencional e de forma racional (RICHARDSON, 2007). Foram entrevistados executivos das empresas Alfa e Beta, distribuídos conforme o Quadro 2.

Quadro 2 - Caracterização dos entrevistados

\begin{tabular}{|c|c|c|c|c|c|}
\hline Empresa & Entrevistado & Cargo & Idade & Sexo & Tempo na empresa \\
\hline Alfa & Alfa 1 & Gerente de Processos & 26 & Masculino & 2 anos \\
\hline Beta & Beta 1 & Life Science \& Health Leader & 52 & Masculino & 18 anos \\
\hline
\end{tabular}

Fonte: Elaborado pelos autores (2020). 


\section{ANÁLISE E DISCUSSÃO DE RESULTADOS}

Para realizar a interpretação seguiu-se os seguintes passos: conectar os tópicos, comparar os resultados com diferentes trabalhos, acrescentar dados adicionais, conectar ao referencial teórico e inserir informações de experiência própria. As informações encontradas nas respostas dos entrevistados foram reduzidas e agrupadas em categorias e, posteriormente, essas categorias foram agrupadas de acordo com suas semelhanças temáticas em metacategorias, conforme apresentado na Figura 3.

Figura 3 - Sistema de categorias

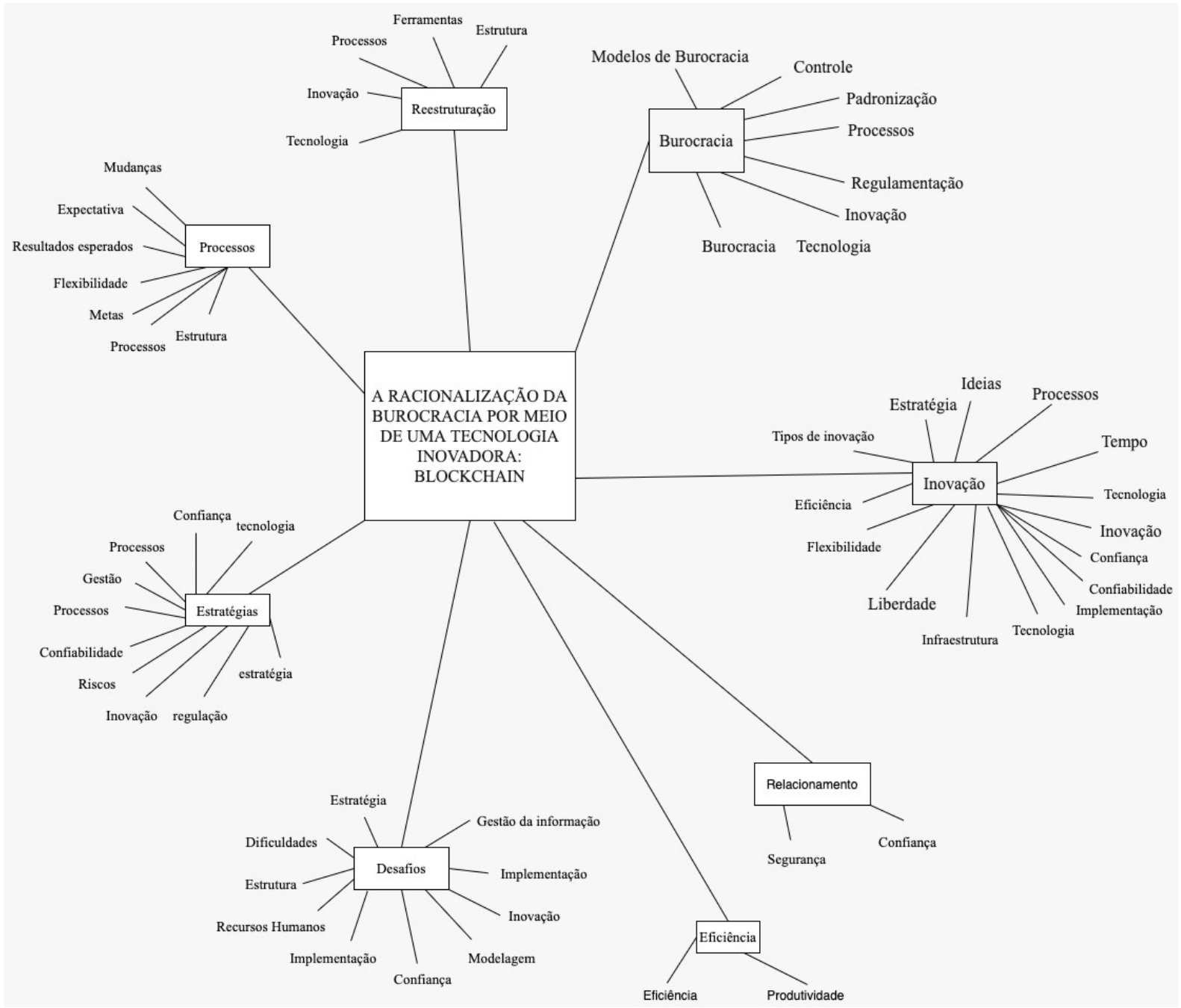

Fonte: Elaborada pelos autores com base em Flores (1994, p. 82).

Dessa maneira, por meio das teorias utilizadas no referencial teórico, foram realizadas as análises detalhas no item 5.1 das categorias e metacategorias apresentadas no sistema proposto por Flores (1994).

\subsection{Análise da empresa Alfa}

Nesta seção foram apresentadas as análises e discussões das metacategorias e categorias referentes a empresa Alfa. 


\subsubsection{Burocracia}

Mediante a metacategoria - Burocracia -, foi possível entender a redução de processos burocráticos na empresa. As categorias observadas são: regulamentação, processos, modelos de burocracia e inovação. De acordo com as respostas do entrevistado Alfa 1, houve com a implementação do blockchain, um aumento na eficiência de processos da empresa.

[...] criou uma ponte entre parceiros de negócios onde pode-se compartilhar os dados de maneira confiável criando uma simetria de informações. Portanto, os processos burocráticos se tornam mais leves pois buscamos informações direto da fonte sem necessidade de solicitações e outros processos.

Segundo Pizza Junior(1984) não se pode mencionar a burocracia sem falar da simplificação de processos.

\subsubsection{Estratégia}

Para a metacategoria - Estratégia - a empresa traça seus planos, metas e objetivos em relação a tecnologia, o foco é em obter resultados com a confiabilidade e segurança dos dados, criando um ambiente colaborativo em tempo real entre os parceiros, com uma governança definida. 0 entrevistado Alfa 1 , esclareceu essa necessidade:

[...] sendo assim, necessário a busca por tecnologias alternativas que passem informações confiáveis para ambos os lados. A falta de informação em tempo real também foi um fator importante para a implementação.

Segundo Gaur, Cuomo e Arun (2019), fica evidente a necessidade das empresas em ter um ambiente colaborativo, e com uma estrutura de incentivos adequada a organização tende a obter os melhores resultados que a implementação do blockchain proporciona.

\subsubsection{Eficiência}

Na metacategoria - Eficiência -, foi possível entender como a inovação do processo gera eficiência na produtividade e um ganho de qualidade no produto. A categoria apresentada é produtividade. Na resposta do entrevistado Alfa 1, a utilização da ferramenta gerou um ganho na produtividade e uma maior eficiência na previsibilidade de demanda.

\footnotetext{
A inovação de processos é importante para a empresa que deseja se diferenciar dos concorrentes, pois com ela a empresa ganha mais flexibilidade, qualidade, diminui o tempo de produção e obtém maior eficiência na sua produção, otimizando, assim, o tempo e lucrando mais. Por isso surge a necessidade de explorar a fundo esse tema e demonstrar os benefícios de se desenvolver uma inovação baseada nos processos.
}

Já no relato da empresa Beta 1, eles foram indiretos no termo, mas deixaram claro que a implementação da tecnologia foi efetiva em suas atividades. "Ele retorna porque você de fato desburocratiza, você fica mais slim, diminuindo funções, funcionalidades, pessoas e processos."

\section{1 .4 Inovação}

Por meio da metacategoria - Inovação-, observaram-se as seguintes categorias: estratégia, processos, confiabilidade, eficiência, tecnologia e tipos de inovação. Com base nas respostas levantadas, pode-se compreender que a inovação possibilitou uma maior eficiência no mercado atuante em relação aos concorrentes e uma redução de custos. Assim como afirma Lemos (2009), as inovações incrementais podem gerar crescimento da eficiência, aumento de produtividade, redução de custos e mudanças que possibilitam a ampliação das aplicações do produto ou processo, como comentou o entrevistado Alfa 1. 


\begin{abstract}
[...] possibilitou uma maior eficiência no mercado que já atuamos. Como é uma tecnologia nova, ainda não consigo mensurar de fato até que ponto pode-se avançar com ela. Mas existe espaço para novos integrantes que têm processos semelhantes aos nossos e de nossos parceiros entrarem na nossa rede e utilizarem os serviços já criados e/ou nos ajudarem a criar novos serviços. Foi uma implementação voltada para o crescimento empresarial através da inovação em relação aos concorrentes com uma vantagem competitiva e em redução de custos.
\end{abstract}

\title{
5.1.5 Processos
}

Essa metacategoria nos trouxe uma visão mais concreta do impacto do blockchain nos processos burocráticos da empresa, de acordo com os entrevistados Alfa 1 e Beta 1, o blockchain vêm atendendo as expectativas conforme previamente planejado, algumas barreiras surgiram na implementação, contudo as equipes estão agindo para encontrar soluções. Em suma, a tecnologia tornou o ambiente de trabalho mais colaborativo com o controle e acesso de forma segura aos dados, racionalizando o peso da burocracia, e colocando em questão suas aplicações e real necessidades, visando eficiência, e resultando em mais confiança nas relações de negócio.

[...] dessa forma otimizamos alguns processos burocráticos, relacionados aos negócios que necessitam de troca de informação com segurança...

[...] o blockchain de fato desburocratiza, diminuindo funções, funcionalidades, pessoas e processos.

Sabendo desse potencial em racionalizar os processos nas empresas, Zambrano (2017) pondera que o governo do Canadá poderia usar o blockchain para complementar e suplementar seus processos, também promovendo essa inovação no setor público. Logo se vê, de acordo com os dados apresentados, que de fato o blockchain pode trazer benefícios nos processos burocráticos, os resultados são evidentes e trazem confiança no negócio, contudo o estudo ainda é recente e barreiras estão surgindo, e como toda inovação dependerá de como os envolvidos da área vão trabalhar para solucioná-los.

\subsubsection{Desafios}

Apurou-se na metacategoria - Desafios -, quais são as barreiras e dificuldades para o funcionamento do blockchaine expansão da sua área de atuação nos processos burocráticos. As categorias classificadas foram: inovação, implementação, dificuldades e processos. Diante das respostas obtidas nas entrevistas, se entendeu que os principais obstáculos giram em torno primeiramente da coordenação entre os parceiros de negócios, de juntarem esforços para realizar mapeamento de processos e integrações necessárias com suas ferramentas.

\footnotetext{
As principais dificuldades foram adaptação dos processos e integrações com os parceiros de negócios e da estruturação de dados de modo que as informações que forem sensíveis para um parceiro ou para nós não fiquem expostas, ou seja, que cada um possa ter a suas permissões adequadas para atuação na
} rede.

Além disso, existe a necessidade de construção de um escopo de projeto que traga vantagens competitivas de uma maneira equivalente ao nível de investimento que está sendo feito pelo participante da rede, como foi afirmado por Ferreira, Pinto e Santos (2017).

\subsubsection{Reestruturação}

Por meio da metacategoria - Reestruturação - considera-se que, ao implementar o blockchain nas empresas há de se adaptar os softwares existentes, e reestruturar a base de dados da mesma criando uma nova base com a tecnologia aplicada. Em seguida, todos os dados relevantes para o negócio nela devem estar armazenados, a implementação deve ocorrer em todas as bases de dados que terão troca de informação para se obter o benefício de segurança e confiabilidade dos dados que a tecnologia provê, o entrevistado Alfa 1 afirmou, sobre a implementação em sua empresa: "[...] tivemos que reestruturar algumas bases de dados da empresa de acordo com a arquitetura da tecnologia e adaptar integrações de softwares já existente..." 
lansiti e Lakhani (2017) também ressaltam que a tecnologia deve estar distribuída nas bases de dados do negócio, a fim de se obter os melhores resultados que a tecnologia oferece.

\subsection{Análise da empresa Beta}

Esta seção discorreu sobre as análises e discussões das metacategorias e categorias que dizem respeito a empresa Beta.

\subsubsection{Burocracia}

Com o reconhecimento da metacategoria - Burocracia -, apurou-se a racionalização de processos burocráticos na implementação do blockchain. As categorias classificadas foram: controle, processos, padronização, tecnologia e regulação. Segundo a resposta do entrevistado Beta 1, os processos burocráticos das empresas em que a tecnologia foi implantada teve um enxugamento de processos e pessoas tendo um impacto positivo na racionalização da burocracia. O entrevistado Beta 1 afirmou: "[...] o blockchain, de fato desburocratiza, limpa o processo, diminui a interação de processos, controles e pessoas."

Pôde-se então, relacionar com a perspectiva de Jun (2018) em que é afirmado que o blockchainé uma forma de burocracia mais eficiente.

\subsubsection{Estratégia}

Apurou-se também na metacategoria Estratégia, quais são as estratégias que suportam a utilização do blockchain nos processos burocráticos. As categorias identificadas são: estratégia, confiança, confiabilidade, processos, tecnologia e riscos. Analisando as respostas do entrevistado Beta 1, notou-se que a colaboração por meio da confiança entre os parceiros é a estratégia implícita quando se trata de um projeto de blockchain. Como a ferramenta traz diversas características que favorecem o compartilhamento de dados, que somada a uma governança bem arquitetada, parceiros de negócios conseguem desfrutar de vantagens competitivas que seriam impossíveis de serem criadas apenas por uma empresa. "[...] o blockchain é parte de um processo de associativismo entre duas ou mais organizações, que podem dividir informações"

Assim, a digitalização de processos, que por si só já traz um ganho expressivo, quando somada a uma ponte de acesso direto aos dados de um parceiro de negócio de uma maneira confiável, pode-se aumentar ainda mais a agilidade e eficiência desses processos. Por isso, assim como afirma Gaur, Cuomo e Arun (2019), é importante destacar que desenvolver uma estrutura de incentivos apropriada é essencial para que todos se motivem e se engajem nesse processo. Entende-se que isso é um trabalho progressivo e que aos poucos, com os parceiros se conhecendo cada vez mais, os ganhos incrementais vão acontecendo ao passo que mais processos que envolvem interação entre parceiros são digitalizados por meio do blockchain.

Por meio da análise de dados constatou-se que os processos burocráticos existentes nas empresas podem ser racionalizados pelo blockchain, trazendo confiança e autenticidade na troca de informações agregadas nesses processos, criando um ambiente mais colaborativo entre parceiros de negócios onde, com a evolução da relação entre os mesmos, há também incentivos para a ampliação do escopo da tecnologia com digitalização de cada vez mais dados, e consequentemente, uma racionalização progressiva. De acordo com as entrevistas feitas nas empresas Alfa 1 e Beta 1, fica claro que o blockchain já é aplicado em alguns processos, as empresas já estão colhendo resultados palpáveis com a tecnologia e se tem a visão do potencial de aplicabilidade em outros diferentes processos, reduzindo os custos e trazendo mais segurança entre os parceiros de negócio.

\subsubsection{Inovação}

Por meio da metacategoria - Inovação -, observou-se as categorias tecnologia e processos. Com base ainda nas respostas levantadas do entrevistado Beta 1, pode-se compreender que a implementação do blockchain passa pela identificação e preocupação entre os processos mais importantes para o negócio. Assim 
como afirma Souza (2008), deve-se priorizar apenas os processos que já existem e os que são cruciais para o resultado do produto ou serviço.

[...] você tem um enxugamento de estrutura, de pessoas, de processos de sites e de mudança de tecnologia para o outro então de uma maneira geral você tem um investimento que esse investimento tem uma razão de ser pelo seu propósito prepara se desburocratizar, para a segurança, por um novo sistema que você vai passar para um novo release. E parte desse investimento. Ele retorna porque você de fato desburocratiza você fica mais slim. Você acaba diminuindo funções e funcionalidades. Pessoas processos então você enxuga um pouco e isso reverte em prol do investimento.

\subsubsection{Desafios}

Por intermédio da metacategoria - Desafios -, observou-se as categorias gestão da informação e confiança. Com base nas respostas levantadas, pode-se entender que as dificuldades do uso da plataforma giraram em torno da adaptação e entendimento dos processos com os parceiros de negócios.

Outro desafio que devemos considerar é a complexidade da tecnologia, para pessoas comuns é basicamente incompreensível o entendimento técnico do blockchain, sua criptografia possui mecanismos que estão além da capacidade da maioria dos usuários.

Para Ferreira, Pinto e Santos (2017) afirma que a adaptação e entendimento dos processos é uma grande dificuldade quando a ferramenta é aplicada em empresas e pessoas que aplicam o blockchain pela primeira vez.

\subsubsection{Reestruturação}

A metacategoria - Reestruturação - acontece devido à implementação do blockchain na empresa, ocorrendo nas diversas bases de dados envolvidas entre os parceiros, com objetivo de apresentar os dados relevantes de maneira segura em um ambiente colaborativo, enxugando a estrutura de pessoal e dos processos burocráticos visando usufruir ao máximo do que a tecnologia oferece, reduzindo custos e logo aumentando o ROI. O entrevistado Beta 1 argumentou que essas mudanças: "Sempre um projeto de tecnologia, independentemente de qual tecnologia seja, você normalmente tem um upside, você tem um enxugamento de estrutura, de pessoas, de processos... ".

lansiti e Lakhani (2017) afirmam que a Reestruturação feita de forma pontual onde o intercâmbio de informação, é crucial para se obter os resultados esperados que o blockchain proporciona: Base de dados distribuída, transmissão de informação ponta a ponta de forma autêntica, segura e transparente.

\subsubsection{Relacionamento}

Com a metacategoria - Relacionamento -, verificou-se o impacto do blockchain no relacionamento entre as empresas. Com as respostas do entrevistado Beta 1 e Alfa 1, foi possível verificar que com a implementação do blockchain houve uma melhora significante no relacionamento e confiança entre as empresas que compartilham as informações.

Eles substituem a confiança, como as empresas não têm confiança uma na outra. Então o blockchain é parte de um processo de associativismo entre duas ou mais organizações, que podem dividir informações.

[...] nossos parceiros se sentem cada vez mais confortáveis com o uso dessa tecnologia. Criamos uma ponte de comunicação e queremos compartilhar cada vez mais informações que podem impactar positivamente em ambas as partes.

Segundo Raj (2019), o blockchain é uma nova forma de construir confiança superando esse problema por meio de uma aplicação descentralizada e segura, garantindo certeza aos usuários. 


\section{CONSIDERAÇÕES FINAIS}

No intuito de compreender quais as implicações da tecnologia blockchain e os seus conceitos nos processos burocráticos, desenvolveu-se um estudo com as empresas Alfa e Beta. Assim, por meio das análises e interpretações das entrevistas obtidas, categorias e metacategorias, buscou-se atender ao problema de pesquisa, objetivo geral e objetivos específicos. Assim, por meio desta pesquisa, foram trazidas alternativas para o uso do blockchain que proporcionaram a racionalização de processos burocráticos, simplificando e remodelando as relações entre as empresas da pesquisa e seus stakeholders e, por intermédio das suas propriedades intrínsecas, geraram mecanismos de incentivo cooperativos e inéditos que ampliaram as eficiências do sistema e sua efetividade.

Resgatando os objetivos específicos, no primeiro deles buscou-se entender como são os processos burocráticos que utilizam blockchain, suas características e peculiaridades. Burocracia, Estratégia, Eficiência, Inovação, Processos, Desafios, Reestruturação e Relacionamento. Observou-se que esses processos normalmente envolvem dois ou mais participantes que transacionam algum tipo de informação que envolvem interesses mútuos. Essas transações são gravadas de maneira imutável, ficam disponíveis para acesso para todos os participantes da rede e servem para auditorias posteriores. Os dados disponíveis podem ser modelados e obedecem a uma lógica de negócio pré-estabelecida pelos participantes em um contrato inteligente.

Quanto ao segundo objetivo, este teve como foco analisar os benefícios que o blockchain traz para os processos burocráticos: Burocracia, Estratégia, Eficiência, Inovação, Processos, Desafios, Reestruturação e Relacionamento. Verificou-se que o blockchain traz confiança entre participantes durante os processos burocráticos que envolvem as suas relações. Com um ecossistema modelado dessa forma, esses participantes possuem incentivos para expor uma parte dos seus dados e essa dinâmica ocasiona uma fluidez maior nos processos burocráticos, pois algumas informações que antes tinham uma grande fricção para serem acessadas, passam a ficar disponíveis de uma maneira muito mais fácil e segura.

O terceiro objetivo específico verificou quais são as barreiras para implementação do blockchain. Notou-se que os principais obstáculos giraram em torno da coordenação entre dois parceiros de negócios para a construção de um escopo de projeto que gere incentivos que justifiquem o investimento na tecnologia e nas integrações da plataforma blockchain com processos, pessoas e softwares da empresa.

Entende-se, dessa forma, que os objetivos estabelecidos neste estudo foram em grande parte alcançados, tratando-se de um exploratório aplicado em um número limitado de casos, citando-se em particular a dificuldade de acessar casos de outras empresas que implementaram com sucesso a tecnologia blockchain.

Como sugestão de estudos futuros, ampliar a análise por meio de comparações entre empresas do mesmo setor e porte, comparando os resultados entre empresas que fazem uso do blockchain com aquelas que atuam com processos burocráticos menos integrados.

\section{REFERÊNCIAS}

ADLER, P. S.; BORYS, B. Two types of bureaucracy: enabling and coercive. USA: Sage, 1996. Disponível em: https://www.jstor.org/stable/2393986. Acesso em: 1 out. 2019.

ALHARBY, M.; VAN MOORSEL, A. Blockchain-based smart contracts: A Systematic Mapping Study. 2017. Disponível em: https://arxiv.org/pdf/1710.06372.pdf. Acesso em: 3 out. 2019.

ANDRADE, R. O. B. de; AMBONI, N. Teoria geral da administração: das origens às perspectivas contemporâneas. São Paulo. 2007.

ANDRIOTTI, R. F.; FILOMENA, T. P.; KLIEMANN NETO, F. J.; CAMPAGNOLO, R. R. A Cost management system for information technology. BASE - Revista de Administração e Contabilidade da UNISINOS, v. 15, n. 4, p. 264-274, 2018. 
ANTONOPOULOS, A.; WOOD, G. Mastering ethereum. 1. ed. Sebastopol: Rachel Head, 2019. Disponível em: https://learning.oreilly.com/library/view/mastering-ethereum/9781491971932/titlepage01.html. Acesso em: 2 out. 2019.

BAPTISTA, V. F. Tecnologia e desenvolvimento social: uma abordagem teórica. Perspectivas em Gestão \& Conhecimento, v. 9, n. 1, p. 4-23, 2019.

BARR, A.; FEIGENBAUM, E. A. The handbook of artificial intelligence. Stanford: Department of Computer Science, Stanford University, 1982.v. 2.

BOURNS, W.F. Bureaucracy adaptation: a comparison of classical Weberian bureaucracy and street-level bureaucracy of police departments. Ann Arbor: The University of Oklahoma, 1994.

$B R O W N E, R$. Five things that must happen for blockchain to see widespread adoption, according to Deloitte. 2018. Disponível em: https://www.cnbc.com/2018/10/01/five-crucial-challenges-for-blockchain-toovercome-deloitte.html. Acesso em: 2 out. 2019.

BUTERIN, V. On public and private blockchains. 2015. Disponível em: https://blog.ethereum.org/2015/08/07/on-public-and-private-blockchains/. Acesso em: 1 out. 2019.

CHRISTENSEN, C. M; The ongoing process of building a theory of disruption. The Journal of Product Innovation Management, v. 23, p. 39-55, 2006.

DÁVILA, G. A.; VARVAKIS, G; LEOCÁDIO, L. Inovação e gerenciamento de processos: uma análise baseada na gestão do conhecimento, 2008.

DRUCKER, Peter F. A disciplina da inovação. Harvard Business Review, São Paulo, p. 80-85, ago. 2004.

DON, B.; RAJAH, D.; OTT, S. Real estate use cases for blockchain technology. [S.I.]: Enterprise Ethereum Alliance - Real Estate Special Interest Group., 2019.

FERREIRA, J.; PINTO F.; SANTOS, C. Estudo de mapeamento sistemático sobre as tendências e desafios do blockchain. Revista Eletrônica Gestão Organizacional, Recife, v. 15, Edição Especial, p. 108-117, 2017.

FLICK, U. Introdução à pesquisa qualitativa. 3. ed. Porto Alegre: Artmed, 2009.

FLORES, J. G. Aproximación interpretativa al contenido de la información textual. In: FLORES, J. G. Analisis de datos cualitativos - aplicaciones a la investigación educativa. Barcelona: PPU, 1994. p. 65-107.

GAUR, N.; CUOMO, J.; ARUN, J. S. Blockchain for business. 1. ed. New York: Addison-Wesley Professional, 2019. Disponível em: https://learning.oreilly.com/library/view/blockchain-forbusiness/9780135581360/title.xhtml. Acesso em: 7 out. 2019.

IANSITI, M.; LAKHANI, K. R. The truth about blockchain. Harvard Business Review. p. 1-11, jan./fev. 2017. Disponível em: https://enterprisersproject.com/sites/default/files/the_truth_about_blockchain.pdf. Acesso em: 20. set. 2019.

JUN, M. Blockchain government - a next form of infrastructure for the twenty-first century. Journal of Open Innovation: Technology, Market, and Complexity, v. 4, n. 7, p. 1-12, 2018.

LAURENCE, T. Blockchain for dummies. 2. ed. New Jersey: For Dummies, 2019. Disponível em: https://learning.oreilly.com/library/view/blockchain-for-dummies/9781119555018/f01.xhtml. Acesso em: 1 out. 2019.

LEMOS, C. Inovação na era do conhecimento. In: LASTRES, H.; ALBAGLI, S. A informação e globalização na era do conhecimento. Rio de Janeiro: Campus, 1999. p. 122-144. 
MARCHISOTTI, G. G.; JOIA, L. A.; CARVALHO, R. B. A representação social de 'cloud computing' pela percepção dos profissionais brasileiros de tecnologia da informação. Revista de Administração de Empresas FVG EAESP, v. 59, n. 1, p. 16-28, jan./fev., 2019.

MATOS, F. R. N.; LIMA, C. A. Organizações modernas e a burocracia: uma "afinidade eletiva"? RAE-eletrônica, v. 6, n. 2, Art. 14, jul./dez. 2007.

MENDONÇA, C. M. C.; ANDRADE, A. M. V.; SOUSA NETO, M. V. Use of IoT, Big Data and artificial intelligence in dynamic capabilities. Pensamento Contemporâneo em Administração, v. 12, n. 1, p. 131-151, 2018.

MOTTA, F. C. P. O que é burocracia. São Paulo: Brasiliense, 1988.

NETTO, C. F. S.; SLONGO, L. A. Marketing metrics, big data and the role of the marketing department. Revista de Administração da UFSM, Santa Maria, v. 12, n. 3, p. 527-543, 2019.

PERSSON, E.; CHAGAS, J.; DASBRINGHENTI, C. Burocracia: Enfoques da produção científica nacional no campo da administração. Revista Gestão Organizacional, v. 8, n. 1, p. 25-50, jan./abr. 2015.

PIOVESAN, A.; TEMPORINI, E. R. Pesquisa exploratória: procedimento metodológico para o estudo de fatores humanos no campo da saúde pública. Rev. Saúde Pública [online], v. 29, n. 4, p. 318-325, 1995.

PIZZA JUNIOR, W. Burocracia(s) e (Des)burocratização. Revista de Administração Pública, v. 18, n. 3, p. 4-17, 1984.

RAJ, K. Foundations of blockchain: The pathway to cryptocurrencies and decentralized blockchain applications. 1. ed. USA: Safis Editing, 2019. Disponível em: https://learning.oreilly.com/library/view/foundations-of-blockchain/9781789139396/cover.xhtml. Acesso em: 5 out. 2019.

RAUCHS, M.; BLADIN, A.; BEAR, K.; MCKEON, S. B. 2nd global enterprise blockchain benchmarking study. 2019. Disponível em: https://ssrn.com/abstract=3461765 Acesso em: 30-set- 2019.

RICHARDSON, R. J. Pesquisa social: métodos e técnicas. 3. ed. São Paulo: Atlas, 2007.

SANTOS, P. V. S. A Introdução de tecnologias a favor da eficiência em operações logísticas: um estudo de caso no setor de serviços. Navus - Revista de Gestão e Tecnologia, v. 9, n. 3, p. 55-68, 2019.

SOUZA, B. Gestão de processos. Paraná: Sebrae, 2008. v. 4.

TIDD, J.; BESSANT, J. Gestão da inovação. 5. ed. Porto Alegre: Bookman, 2015. 633 p.

VASCONCELOS, F. C. Racionalidade, autoridade e burocracia: as bases da definição de um tipo organizacional pós-burocrático. Revista de Administração Pública, v. 38, n. 2, p. 199-220, 2004.

WEBER, M. História geral da economia. São Paulo: Mestre Jou, 1963.

ZAMBRANO, R. Unpacking the disruptive potential of blockchain technology for human development. Ottawa: Ruhiya Kris Seward, 2017. Disponível em: https://idl-bnc-

idrc.dspacedirect.org/bitstream/handle/10625/56662/IDL-56662.pdf. Acesso em: 1 out. 2019.

ZHENG, Z.; XIE, S.; DAI, H.; WANG, H. Blockchain challenges and opportunities: a survey. 2018. Disponível em:

https://www.researchgate.net/publication/328271018_Blockchain_challenges_and_opportunities_a_survey. Acesso em: 30 set. 2019. 